\title{
Prevalence and Correlates of Depressive Symptoms Among International Students: Implications for University Support Offices
}

\author{
Noel L. Shadowen ${ }^{\mathrm{a}}$, Ariel A. Williamson $^{\mathrm{b}}$, Nancy G. Guerra ${ }^{\mathrm{c}}$, \\ Ravichandran Ammigan ${ }^{d}$ and Matthew L Drexler ${ }^{d}$
}

\begin{abstract}
International students often experience significant challenges and difficulties adjusting to their new campus and university environment abroad. As a result, understanding the unique needs of these students has become an important priority for many university administrators and mental health professionals amid growing health concerns faced by members of this community. This study examines the prevalence and correlates of depressive symptoms in a sample of international students enrolled in a mid-size U.S. university. A hierarchical multiple regression model revealed that poor English fluency, increased acculturative stress, and perceived discrimination were associated with higher levels of depressive symptoms, whereas increased social support was associated with lower levels of depressive symptoms. Implications for university administration and support services are discussed.
\end{abstract}

Keywords: acculturative stress, depressive symptoms, international students, perceived discrimination, social support

\section{Introduction}

As the world becomes increasingly globalized, the number of students from foreign countries studying at U.S. universities has increased dramatically, with enrollments of international students increasing by $85 \%$ over the past decade (Institute of International

\footnotetext{
${ }^{a}$ Center for Training, Evaluation, \& Community Collaboration at the, University of Delaware.

b Children's Hospital of Philadelphia.

${ }^{\mathrm{c}}$ School of Social Ecology and Professor, Department of Psychology and Social Behavior, University of California, Irvine.

$\mathrm{d}$ Office for International Students and Scholars, University of Delaware.

${ }^{凶}$ Corresponding author: nshadow@udel.edu
} 
Education, 2017). China and India are the two biggest "sender" countries, collectively providing almost $50 \%$ of the international students who currently study in the United States. The presence of international students on campus offers significant benefits to universities. For example, international students and their dependents contributed $\$ 36.9$ billion to the U.S. economy during the 2016-2017 academic year (Association of International Educators, 2017). More importantly, international students add significant diversity and educational value to the academic environment on campus by bringing to the classroom different cultural backgrounds, experiences, and worldviews and acting as "cultural ambassadors" for their home country (Lee \& Rice, 2007; Luo \& Jamieson-Drake, 2013; Sandhu \& Asrabadi, 1994). International students can play a vital role in providing opportunities for global engagement and supporting the campus internationalization efforts at institutions of higher education.

Despite the explosion of growth in international students studying on U.S. campuses, especially from Asian countries, few empirical quantitative studies have examined the challenges and difficulties associated with adjusting to life in the U.S. that these students face (Mori, 2000; Poyrazli, Thukral, \& Duru, 2010). Mori (2000) labeled international students as "one of the most quiet, invisible, underserved groups on the American campus" (p. 143). There is a continuing need to better understand mental health concerns among international students, as a wide range of adjustment challenges may significantly increase their risk for such problems (Pederson, 1991; Sumer, Poyrazli, \& Grahame, 2008).

Indeed, available evidence suggests that international students are at a greater risk for psychological problems than the general U.S. university student population (Andrade, 2006; Liu, 2009; Mori, 2000; Sandhu \& Asrabadi, 1994). In the US, depression is one of the most common mental health concerns. That said, little research has comprehensively examined the prevalence of depressive symptoms among international students. A study by Rice, Choi, Zhang, Morero, and Anderson (2012) that included only Chinese and Indian graduate students in the US reported that $36.7 \%$ of these students met or exceeded the clinical cut-off point on a depressive symptoms screening measure. Although it is difficult to compare studies screening for depressive symptoms due to differing methodologies and instruments, this rate is higher than the $11 \%-30 \%$ of general U.S. college students who are reported to screen positively for depression (American College Health Association, 2017; Eisenberg, Gollust, Golberstein, \& Hefner, 2007; Eisenberg, Hunt, \& Speer, 2013; Lipson, Gaddis, Heinze, Beck, \& Eisenberg, 2015).

While some studies have found that depressive symptoms vary across regions based on a series of different factors (e.g., Botha, Shamblaw, \& Dozois, 2017; Steptoe, Tsuda, Tanaka, \& Wardle, 2007), elevated expressions of depressive symptoms among international students may be determined by the level of internalized cultural identity they carry from their home cultures (Chang, Jetten, Cruwys, \& Haslam, 2017). Steptoe et al. (2007) compared depressive symptoms in college students across 23 different countries and found a pattern of higher depressive symptoms in non-Western countries, with especially elevated rates in individuals from Pacific Asian societies. Given that international students, particularly Asian students, may enter U.S. institutions with an already heightened propensity for depression, it is critical to further understand the specific challenges these students face that can support prevention and intervention 
initiatives. Depressive symptoms are particularly important to examine, as they are among the most common presenting complaints for international students who seek help from university counseling centers (Kawamoto et al., 2018; Yi, Lin, \& Kishomoto, 2003). Additionally, depressive symptoms in young adult college students have been linked to a variety of severe negative consequences, including negative consequences related to alcohol use and drinking (Martens et al., 2008), academic impairment (Hill, Yaraoslavsky, \& Petit, 2015), early academic drop out (Eisenberg, Golberstein, \& Hunt, 2009), tobacco use, unwanted sexual experiences, and other forms of violence (Mackenzie et al., 2012). Given that young adulthood is a peak period for the onset of depression (Cujipers et al., 2015), it is particularly important that universities be aware of the prevalence and potential negative outcomes associated with depression in their students.

\section{Literature Review}

\section{Correlates of Depressive Symptoms Among International Students}

In addition to examining prevalence rates of depression among international students, it also is important to understand factors that contribute to elevated rates or serve as buffers to help students psychologically cope with challenges and stressors. Indeed, international students face several unique challenges above and beyond typical adjustment to collegerelated stress that can compromise their transition to life in the US. These challenges include difficulties with English, acculturative stress, and discrimination (Andre de Araujo, 2011; Pedersen, 1991; Sumer et al., 2008; Yeh \& Inose, 2003). Although language difficulties are not typically associated with mental health problems, for some international students poor English language fluency can lead to several problems. For example, some international students may have greater difficulty understanding lectures, keeping up with class readings and notes, and interacting with other students in English (Pedersen, 1991). Students may find that their lack of proficiency in English prohibits comfortable social interactions and, in turn, the development of relationships with host-country students outside of class. English fluency has been linked both to cultural adjustment stress and to international students' academic adjustment (Poyrazli \& Kavanaugh, 2006). Studies have also shown a link between students' English abilities and overall adaptation and academic success at a host university (Crano \& Crano, 1993; Ying \& Liese, 1994).

English fluency is one aspect of the broader acculturation process that international students experience during their transition to a new culture. Acculturation is defined as the behavioral and psychological changes that an individual encounters as he or she enters a new culture and has contact with people from different cultural groups (Atri, Sharma, \& Cottrell, 2007). Acculturative stress refers to the specific adjustment stress associated with the transition from one's home culture to a new cultural environment (Sandhu \& Asrabadi, 1994). Prior research has shown that there are regional differences in acculturation difficulty. The adjustment process is generally more stressful when the cultural differences between the home and host cultures are greater (Pedersen, 1991; Sam, 2001). Yeh and Inose (2003) found that students from Asia, Latin America, and Africa experienced higher levels of acculturative stress than did students from European countries studying at the same U.S. university. In a similar study by Poyrazli et al. 
(2010), African international students experienced the highest levels of acculturative stress, followed by Asian, Middle Eastern, and Latino students, with European students showing the lowest levels of acculturative stress.

These regional differences in acculturative stress may be due to the fact that students from cultures more dissimilar to the U.S. experience a more intense culture clash during their transition to the host culture, or because they are less likely to "blend in" with the U.S. student population than are White European international students (Poyrazli et al., 2010). Given these findings, it seems likely that much of the stress that international students experience during their transition to the host environment is not simply due to homesickness or general adjustment issues but rather specifically to adjustment related to cultural differences.

International students' ethnic and racial differences as well as their lack of English language fluency may cause some students to be targets of discrimination (Sam, 2001). Discrimination typically is defined as negative events, such as biases and prejudice, that are based on group membership (Feagin \& Eckberg, 1980; Hanassab, 2006). Immigrants and international students report experiencing higher levels of discrimination compared with levels experienced by domestic, U.S. students (Poyrazli \& Lopez, 2007). Previous empirical work with immigrant populations has shown that perceived discrimination is one of the major acculturation-related stressors associated with negative mental health outcomes and poor psychological well-being (Jasinskaha-Lahti, Liebkind, Jaakkola, \& Reuter 2006). Interestingly, perceived discrimination tends to increase as students spend more time in the US (Poyrazli \& Lopez, 2007).

Discrimination may exacerbate the isolation and stress that already accompany a transition to a new environment. For example, increased discrimination has been associated with higher rates of depression among Asian students, above and beyond general everyday stress (Wei, Ku, Russell, Mallinckrodt, \& Liao, 2008). Additionally, studies have shown that perceived discrimination lowers students' satisfaction with attending a U.S. university (Wadsworth, Hecht, \& Jung, 2008) and can negatively impact students' educational experience (Karuppan \& Barari, 2011).

On the other hand, strong social support networks can potentially facilitate the transition to studying in the US, particularly for students from collectivistic societies. Collectivistic cultures tend to place an emphasis on relationships and social connectedness (Cross, 1995), and a collectivist cultural orientation is associated with greater vulnerability to social experiences (Sumer et al., 2008). Research indicates that strong social networks may serve to buffer an individual's vulnerability to stressful situations by preventing a situation from being perceived as stressful or by facilitating a positive behavioral response to stress (Cohen \& Wills, 1985).

Given their difficulties with language, acculturative stress, and perceived discrimination, the support of a social network may be quite important for international students, who generally feel a lack of adequate social support and connectedness in the host country (Yeh \& Inose, 2003). The loss of social support from relationships in their home country can have a negative influence on their psychological well-being (Bhochhibhoya, Dong, \& Branscum, 2017; Chuah \& Singh, 2016; Pedersen, 1991). Social support may play a crucial 
role in protecting students from the isolation and stress associated with the adjustment to university life in a new country.

\section{Supporting International Students}

The dramatic growth of international student enrollment at U.S. institutions in recent years has arguably presented university administrators and service units with a number of challenges for how to best support this community and ensure their successful transition to campus (Kelo, Rogers, \& Rumbley, 2010). The complexity of adjusting to a new academic, social, and cultural setting, coupled with the uncertainties surrounding immigration regulations and travel safety and security, can be very confusing and stressful for international students (Msengi, 2004; Perrucci \& Hu, 1995). It is therefore critical that institutions remain proactive and intentional at offering strong support services that meet the changing needs and enrich the experience of these students.

Typically, support services for international students at U.S. institutions are organized through a dedicated support office, which is generally responsible for providing a number or services including advising on visa and employment options, cultural programming and campus-wide engagement opportunities, and a variety of resources that help students navigate occasional academic and social issues (Briggs \& Ammigan, 2017; Wood \& Kia, 2000). It is common for these support offices to collaborate extensively with other student affairs units, such as the counseling center, student wellness, and health services, to reach a broader audience and increase access to a wider range of services on campus. Campus counseling centers and other support offices typically have limited resources, and therefore it is crucial to understand the experiences of international students regarding adjustment and mental health symptoms, and how best these students can be supported.

\section{Method}

\section{The Present Study}

The purpose of this study was to further our understanding of negative mental health outcomes in international students by examining the prevalence and correlates of depressive symptoms on a U.S. campus, in order to inform relevant college student services. The first aim of this study was to document the prevalence of depressive symptoms among international students. We were interested in identifying the percentage of international students who met established clinical cut-offs for internalizing problems on widely used screening measures of depressive and anxiety symptoms. The second aim of this study was to examine the associations between depressive symptoms and lack of English fluency, and the presence of acculturative stress, perceived discrimination, and social support. Due to the importance of communication skills when adjusting to a host culture, we hypothesized that international students with poor self-reported English fluency would exhibit higher depressive symptoms than those who felt more confident and comfortable interacting in the host culture language. We also hypothesized that higher levels of acculturative stress and perceived discrimination would be associated with more depressive symptoms, due to the association of stress with depression in past research. Finally, we hypothesized that individuals who reported having a large social support group 
to turn to would report fewer depressive symptoms than individuals without a strong base of social support.

\section{Participants}

Participants were drawn from a potential pool of 1,991 international students enrolled at a mid-size 4-year university in the Mid-Atlantic region (hereafter referred to as "the university site"). A total of 490 international students (254 males, 236 females) consented to participate in the study and completed the survey. On average, students were 24.9 years old $(S D=4.28)$, with $46.0 \%$ having spent 2 years or less living outside of their home country. Approximately $70.2 \%$ of the students were enrolled in a graduate program, and $29.8 \%$ were undergraduate students. Participants originated from nine different regions of the world, including Africa (2.0\%), Central America and the Caribbean (2.4\%), Central Asia $(0.8 \%)$, East and Southeast Asia (69.8\%), Europe (4.5\%), North America (including Mexico; 0.6\%), the Middle East (4.1\%), South America (4.7\%), and South Asia (11.0\%). World region identifications were based on the official designations of the U.S. government in the CIA World Fact Book (Central Intelligence Agency, 2017). Together, students from Asia constituted $81.6 \%$ of the sample. Across the full sample, 92.9\% reported that English was not their first language.

\section{Procedure}

The International Student Services office at the university site emailed the currently enrolled international undergraduate and graduate students an introductory letter that explained the present study and provided a link to a Qualtrics website where students could anonymously complete the study survey. Students gave consent to participate in the study in compliance with the overseeing university's Institutional Review Board. To encourage participation, students who completed the survey within a 3-week period were given the opportunity to enter a raffle drawing for a $\$ 100$ gift card to a local home goods store. To ensure participant anonymity, participants were directed to another, de-linked site if they wished to enter their email addresses for the raffle. Three reminder emails were sent to the students over the course of the 3 weeks that the survey was available. Of the 1,991 students who were invited to participate, 490 participants completed the minimum number of scales to be included in the sample. The response rate was approximately $24.6 \%$, which is comparable to other online survey research with students (Duru \& Poyrazli, 2011; Rice et al., 2012; Sumer et al., 2008).

\section{Measures}

Participants completed a demographic questionnaire and a series of measures designed to assess their depressive and anxiety symptoms, English fluency, acculturative stress, perceived discrimination, and levels of social support. We used existing scales or adapted existing scales when necessary. 


\section{Demographics}

Participants were asked to indicate their region of origin, gender, age, and educational level.

\section{Depressive Symptoms}

We used the 20-item Center for Epidemiological Studies-Depression Scale (CES-D) to screen for depressive symptoms. Items were rated on a 4-point scale, and total CES-D scores could range from 0 to 60 , with higher scores indicating more depressive symptoms. A score of 16 and above is the typical cut-off score for screening positively for clinically significant depressive symptoms (Radloff, 1977). Items on the CES-D assess feelings of worthlessness, helplessness, hopelessness, appetite loss, and sleep disturbances (Radloff, 1977). A sample item from this scale is "I did not feel like eating; my appetite was poor" $(\alpha=.90)$. The CES-D is a widely used depression screening inventory for non-clinical populations and has been used in prior studies with international students in the US (Constantine, Okazaki, \& Utsey, 2004; Rice et al., 2012) as well as with diverse Latino (Torres, 2010) and Asian communities (Wei, Heppner, Ku, \& Liao, 2010). It has also been used for research purposes in various Asian countries (Mackinnon, McCallum, Andrews, \& Anderson, 1998).

\section{Anxiety Symptoms}

The Beck Anxiety Inventory (BAI) is a 21-item scale that was used to measure the severity of anxiety symptoms (Beck, Epstein, Brown, \& Steer, 1988). Items are rated on a 4-point scale, and possible scores can range from 0 to 63 , with higher scores indicating greater anxiety symptomatology. Participants were asked to indicate how often they experienced anxiety symptoms such as a "fear of the worst happening" in the past month $(\alpha=.97)$.

\section{English Fluency}

English fluency was examined using two items developed for the present study that were rated on a 5-point scale. The two items were (1) "How would you rate your current ability to speak and interact in English?" and (2) "How would you rate your confidence in speaking English in front of native English speakers?” Scores on this scale could range from 2 to 10, with higher scores indicating greater English fluency $(\alpha=.91)$.

\section{Acculturative Stress}

The Acculturative Stress Scale for International Students (ASSIS) is a 36-item 5-point scale designed to assess the stress associated with acculturation among international students (Sandhu \& Asrabadi, 1994). For this study, we adapted the wording of some items for international students who may not understand idiomatic phrases in English and removed two items that were irrelevant for this specific population. For example, the question "I feel angry that my people are considered inferior here" was revised to read "I feel angry that people from my country are considered inferior here" (italics added). The ASSIS consists of seven subscales: Perceived Discrimination (eight items), Homesickness (four items items), 
Perceived Hate (five items), Guilt (two items), Fear (four original, three in our adapted version), Stress Due to Change/Culture Shock (three items), and Miscellaneous Concerns (10 items, nine in our adapted version). For this study we used the total scale score, which could range from 34 to 170 , with higher scores indicating greater acculturative stress $(\alpha=$ $.96)$.

\section{Perceived Discrimination}

Perceived discrimination was assessed using a 9-item scale that focused on common experiences of chronic and routine discrimination (Williams, Yu, \& Jackson, 1997). Participants were asked to indicate how often they experienced certain discrimination events such as, "people act as if they are better than you" $(\alpha=.95)$. Items were rated on a 4point scale and possible total scores could range from 0 to 27 , with higher scores indicating higher levels of perceived discrimination.

\section{Social Support}

Originally, we intended to use a 4-item scale to measure social support, which included questions about a students' number of friends from the same region, American friends, how many people they could turn to for support if needed, and how satisfied they were with their current level of social support. However, the coefficient alpha for this combined scale was very poor ( $\alpha=.58$ ) so we decided to just use one item from the scale as our measure of social support. Social support was measured with the one item on a 5-point scale. The item asked participants "How many people here in [city] do you feel you could turn to for support or help if needed?" Scores could range from 1 to 5 , with higher scores indicating greater levels of local social support. This question was designed to rate the students' own perceptions of the availability of social support in their host community.

\section{Data Analysis}

All analyses were conducted in IBM SPSS Statistics for Windows (Version 23). First, we examined the prevalence of internalizing problems by gender, education status (graduate versus undergraduate), and region (Asian versus non-Asian) using the prescribed cut-off score of 16 for clinically significant depressive symptoms on the CES-D scale (Radloff, 1977). Although anxiety was only included as a covariate in the present study, we also examined the prevalence of clinically significant anxiety using the BAI cut-off score of 19 to indicate moderate to severe anxiety (Beck et al., 1988). We then performed chi-square analyses to determine if there were significant differences between students exceeding cutoffs on internalizing problems by gender, education status, and region.

To test hypotheses related to correlates of depressive symptoms, we conducted a hierarchical multiple regression analysis using depressive symptoms as the outcome variable. All continuous predictors were centered to facilitate interpretation of the intercept. Dummy codes were created for gender (female $=1$ ), education status (graduate students $=1$ ), and region (Asian region $=1$ ). In these analyses, the demographic variables of gender, education status, and region were entered in Step 1 as control variables. Additionally, because anxiety is a construct that is generally highly correlated 
with depression and was correlated with depression at $r=.70(p<.001)$ in the present sample, we also controlled for anxiety levels in Step 1 of the regression. English fluency was entered as a predictor variable in Step 2 of the analysis, as this variable was hypothesized to be uniquely associated with depressive symptoms in the current sample. In Step 3 of the analysis, we simultaneously entered acculturative stress and perceived discrimination; these variables were entered together given their high degree of conceptual overlap. We then tested the relationship between social support and the depressive symptoms in Step 4 of the regression analysis, to test whether social support buffered depressive symptoms above and beyond the risk factors entered into the regression at Steps 2 and 3.

\section{Results}

\section{Preliminary Analyses}

An examination of study variable characteristics showed that the depressive symptoms outcome variable was slightly positively skewed. After performing a log transformation of this outcome, we used both the non-transformed and transformed variable and found no difference in results. Accordingly, all results reported below utilize the non-transformed outcome to facilitate interpretation.

\section{Prevalence of Internalizing Problems}

Table 1 summarizes the prevalence and mean levels of depressive and anxiety symptoms above clinical cut-offs according to various demographic characteristics. The number of total international students meeting or exceeding the cut-off score for clinically significant depressive symptoms was 222 , or $45.3 \%$ of the sample. The number of students meeting or exceeding the screening cut-off for anxiety symptoms was 121 , or $24.7 \%$ of the sample. Chi-square analyses revealed significant differences in the percentage of students meeting clinical cut-offs depending on various demographic characteristics. In the undergraduate student group, $62.3 \%$ of students met the cut-off criteria for depressive symptoms, which was greater than the $38.1 \%$ of graduate students who met or exceeded the cut-off, $\chi^{2}$ (1, $\mathrm{N}=490)=24.32, \mathrm{p}<.001$. There were also significant differences between the $43.2 \%$ of undergraduate students and $16.9 \%$ of graduate students who met the clinical cutoff for moderate or severe anxiety symptoms $\chi^{2}(1, \mathrm{~N}=490)=38.10$, $\mathrm{p}<.001$. With regard to regional differences, $27.2 \%$ of Asian international students reported anxiety symptomatology that met the cut-off point for moderate to severe anxiety symptoms, while only $13.3 \%$ of non-Asian students met this clinical cut-off $\chi^{2}(1, \mathrm{~N}=490)=7.65, \mathrm{p}$ $<.01$. There were no significant differences by gender for depressive or anxiety symptoms.

Note. Chi-square analyses for significant differences by group. ${ }^{*} p<.05{ }^{* *} p<.01{ }^{* * *} p<$ .001

\section{Bivariate Correlations}

Table 2 reports zero-order bivariate correlations among study variables, along with means and standard deviations. Depression and anxiety were strongly positively correlated ( $\mathrm{r}$ $=.70, \mathrm{p}<.001)$, as would be expected given the literature on internalizing concerns 
Table 1. Prevalence of clinically significant depressive and anxiety symptoms by demographic variables $(\mathrm{N}=490)$

\begin{tabular}{lcccc}
\hline & $\begin{array}{c}\text { Depressive } \\
\text { symptoms }\end{array}$ & \multicolumn{3}{c}{$\begin{array}{c}\text { Anxiety } \\
\text { symptoms }\end{array}$} \\
\hline $\begin{array}{l}\text { Demographic } \\
\text { variables }\end{array}$ & $\mathrm{M}(\mathrm{SD})$ & $\begin{array}{c}(\%) \text { above } \\
\text { cutoff }\end{array}$ & $\mathrm{M}(\mathrm{SD})$ & $\begin{array}{c}\text { (\%) above } \\
\text { cutoff }\end{array}$ \\
Male & $16.42(09.91)$ & $118(46.5 \%)$ & $11.30(12.58)$ & $66(26.0 \%)$ \\
Female & $16.47(10.17)$ & $104(44.1 \%)$ & $11.96(13.02)$ & $55(23.3 \%)$ \\
Asian & $16.85(10.04)$ & $185(46.2 \%)$ & $12.32(13.24)$ & $109(27.2 \%)^{* *}$ \\
Non-Asian & $14.63(9.83)$ & $37(41.1 \%)$ & $8.51(10.02)$ & $12(13.3 \%)^{* *}$ \\
& & & & \\
Undergrad & $18.20(10.57)$ & $91(62.3 \%)^{* * *}$ & $16.29(15.23)$ & $63(43.2 \%)^{* * *}$ \\
Graduate & $14.96(9.42)$ & 131 & $9.63(11.03)$ & $58(16.9 \%)^{* * *}$ \\
& & $(38.1 \%)^{* * *}$ & & \\
Entire sample & $16.44(10.03)$ & $222(45.3 \%)$ & $11.62(12.79)$ & $121(24.7 \%)$ \\
\hline
\end{tabular}

(Creamer, Foran, \& Bell, 1995; Jansson-Frojmark \& Lindblom, 2008). Acculturative stress and perceived discrimination were also strongly positively correlated $(\mathrm{r}=.66, \mathrm{p}<.001)$. English fluency showed a small negative correlation with anxiety $(\mathrm{r}=-.17, \mathrm{p}<.001)$ and depression $(\mathrm{r}=-.11, \mathrm{p}<.05)$. Social support was inversely related to study variables, including anxiety $(\mathrm{r}=-.23, \mathrm{p}<.001)$, and positively to English fluency $(\mathrm{r}=.19, \mathrm{p}<.001)$.

Table 2. Zero-order bivariate correlations among study variables $(\mathrm{N}=490)$

\begin{tabular}{lcccccc}
\hline \multicolumn{1}{c}{ Variables } & 1 & 2 & 3 & & & \\
\hline 1. Depressive symptoms & - & & & & & \\
2. Anxiety symptoms & $.70^{* * *}$ & - & & & & \\
3. English fluency & $-.17^{* * *}$ & $-.11^{*}$ & - & & & \\
4. Acculturative stress & $.56^{* * *}$ & $.52^{* * *}$ & $-.25^{* * *}$ & - & & \\
5. Perceived discrimination & $.63^{* * *}$ & $.71^{* * *}$ & $-.15^{* *}$ & $.66^{* * *}$ & - & \\
6. Social support & $-.23^{* * *}$ & -.06 & $.19^{* * *}$ & $-.13^{* *}$ & -.08 & - \\
M & 16.44 & 11.62 & 7.65 & 67.75 & 5.43 & 3.37 \\
SD & 10.00 & 12.78 & 1.69 & 20.20 & 5.78 & 1.09 \\
Range & $0-48$ & $0-63$ & $2-10$ & $33-132$ & $0-27$ & $1-5$ \\
\hline
\end{tabular}

${ }^{*} p<.05^{* *} p<.01^{* * *} p<.001$

\section{Correlates of Depressive Symptoms}

Table 3 summarizes the hierarchical regression analysis. In the first step, the demographic and anxiety variables accounted for significant variation in depressive symptom scores, 
Table 3. Results of hierarchical regression model $(\mathrm{N}=490)$

\begin{tabular}{|c|c|c|c|c|c|}
\hline & Variable & $\mathrm{B}(\mathrm{SE})$ & $\beta$ & $t$ & $\begin{array}{c}\text { Semi-partial } \\
\text { correlation }\end{array}$ \\
\hline \multicolumn{6}{|l|}{ Step 1} \\
\hline & Female & $-0.40(0.65)$ & -.02 & -0.62 & -.02 \\
\hline & $\begin{array}{l}\text { Graduate } \\
\text { student }\end{array}$ & $-1.39(0.73)$ & -.06 & -1.92 & -.06 \\
\hline & Asian region & $0.16(0.84)$ & .01 & 0.19 & .01 \\
\hline & Anxiety & $0.54(0.03)$ & .70 & $20.67^{* * *}$ & .66 \\
\hline \multicolumn{6}{|l|}{ Step 2} \\
\hline & Female & $-0.42(.064)$ & -.02 & -0.65 & -.02 \\
\hline & $\begin{array}{l}\text { Graduate } \\
\text { student }\end{array}$ & $-1.22(0.72)$ & -.06 & -1.69 & -.05 \\
\hline & Asian region & $-0.60(0.87)$ & -.02 & -0.69 & -.02 \\
\hline & Anxiety & $0.54(0.03)$ & .68 & $20.65^{* * *}$ & .66 \\
\hline & $\begin{array}{l}\text { English flu- } \\
\text { ency }\end{array}$ & $-0.57(0.20)$ & -.10 & $-2.86^{* *}$ & -.09 \\
\hline \multicolumn{6}{|l|}{ Step 3} \\
\hline & Female & $-0.41(0.61)$ & -.02 & -0.67 & -.02 \\
\hline & $\begin{array}{l}\text { Graduate } \\
\text { student }\end{array}$ & $-0.96(0.69)$ & -.04 & -1.39 & -.04 \\
\hline & Asian region & $-1.72(0.84)$ & -.07 & $-2.05^{*}$ & -.06 \\
\hline & Anxiety & $0.39(0.03)$ & .49 & $11.37^{* * *}$ & .34 \\
\hline & $\begin{array}{l}\text { English } \\
\text { fluency }\end{array}$ & $-0.34(0.19)$ & -.06 & -1.75 & -.05 \\
\hline & $\begin{array}{l}\text { Acculturative } \\
\text { stress }\end{array}$ & $0.11(0.02)$ & .23 & $5.45^{* * *}$ & .16 \\
\hline & Discrimination & $0.21(0.09)$ & .12 & $2.43^{*}$ & .07 \\
\hline \multicolumn{6}{|l|}{ Step 4} \\
\hline & Female & $-0.70(0.60)$ & -.04 & -1.17 & -.03 \\
\hline & $\begin{array}{l}\text { Graduate } \\
\text { student }\end{array}$ & $-1.21(0.67)$ & -.06 & -1.80 & -.05 \\
\hline & Asian region & $-1.07(0.83)$ & -.04 & -1.30 & -.04 \\
\hline & Anxiety & $0.39(0.03)$ & .49 & $11.67^{* * *}$ & .34 \\
\hline & $\begin{array}{l}\text { English flu- } \\
\text { ency }\end{array}$ & $-0.14(0.19)$ & -.02 & -0.70 & -.02 \\
\hline & $\begin{array}{l}\text { Acculturative } \\
\text { stress }\end{array}$ & $0.10(0.20)$ & .20 & $5.20^{* * *}$ & .15 \\
\hline & Discrimination & $0.20(0.08)$ & .12 & $2.38^{*}$ & .07 \\
\hline & $\begin{array}{l}\text { Social Sup- } \\
\text { port }\end{array}$ & $-1.44(0.28)$ & -.16 & $-5.12^{* * *}$ & -.15 \\
\hline
\end{tabular}

Note. Step $1 R^{2}=.50$, Step $2 R^{2}=.51$, Step $3 R^{2}=.56$, Step $4 R^{2}=.59{ }^{*} p<.05,{ }^{* *} p<.01,{ }^{* * *} p<.001$ 
$F(4,485)=120.92, p<.001, R^{2}=.50$. There was also a significant, positive relationship between anxiety scores and depression scores $(B=0.54, p<.01)$. In Step 2, English fluency was significantly associated with depressive symptoms, such that lower levels of English fluency were associated with higher levels of depressive symptoms $(B=-0.57, p<.01)$, $\left(\Delta R^{2}=.01\right), \Delta F(1,484)=8.20, p<.01, R^{2}=.51$. An examination of the change in $R^{2}$ showed that adding English fluency to the model did not greatly increase the variance explained in depressive symptoms. At Step 3, we found that higher levels of both acculturative stress ( $B$ $=0.11 p<.001)$ and perceived discrimination $(B=0.21, p<.05)$ were significantly related to higher levels of depressive symptoms $\left(\Delta R^{2}=.06\right), \Delta F(2,482)=30.38, p<.001, R^{2}=$ .56. However, with the acculturative stress and perceived discrimination variables added to the model there was no longer an observable effect for English fluency on depression outcomes $(B=-0.34, n s)$. In Step 4 we entered social support into the model $(B=$ $-1.44, p<.001)$. The effect for acculturative stress and perceived discrimination remained statistically significant in this step. After controlling for the aforementioned demographic variables, anxiety symptoms, acculturative stress, and perceived discrimination, we found a significant effect for social support, such that higher levels of social support were associated with lower levels of depressive symptoms $\left(\Delta R^{2}=.02\right), \Delta F(1,481)=26.19, p<$ $.001, R^{2}=.59$. Overall, the full model accounted for $59 \%$ of the variance in international students' depressive symptoms.

\section{Discussion}

In this study we investigated the extent to which international students' lack of English fluency and their experiences of acculturative stress, discrimination, and social support were associated with depressive symptoms. In addition, we explored whether demographic variables were associated with these depressive symptoms. We found that overall international students reported high levels of depressive and anxiety symptomology, with $45.3 \%$ of students meeting the clinically significant screening cutoff for depression on the CES-D measure, and $24.7 \%$ of students screening positive for moderate-to-severe anxiety symptoms on the BAI. We found that undergraduate students tended to report higher on both the depression and anxiety measures, as $62.3 \%$ endorsed significant levels of depressive symptoms and $43.2 \%$ endorsed moderate-to-severe levels of anxiety symptoms. This is consistent with the pattern of slightly higher depressive and anxiety symptoms reported among U.S. undergraduate students compared to graduate students (Eisenberg et al., 2007) but has not to our knowledge been extensively and specifically explored in international student populations. Additionally, significantly more Asian international students reported anxiety symptoms above the clinical cut-off for moderate-to-severe anxiety symptoms than did non-Asian international students. This may be because Asian students find the changes related to adjustment to the US to be more anxiety-provoking or because they have more difficulties overall with the adjustment. These findings are consistent with prior research indicating that Asian international students have more difficulty adjusting to the norms and values of the host culture than do international students from other regions (Hsieh, 2006).

Our first hypothesis, which was that English fluency would be associated with depressive symptoms outcomes, was partially supported. There was a significant 
association between English fluency and depressive symptoms in analyses examining English fluency and other demographic variables in relation to depressive symptoms. Having fewer difficulties with English language fluency was associated with lower levels of depressive symptoms, consistent with the notion that increased communication and self-expression abilities may be associated with fewer mental health concerns. However, when English fluency was considered in the context of acculturative stress and perceived discrimination, the effect of English fluency on depressive symptoms was no longer significant. This may be because the ability to communicate effectively in the language of the host culture is critical to the acculturation process, and when acculturative stress and English fluency are examined simultaneously, the effect of English proficiency is no longer relevant to the depressive symptoms outcome.

Results supported our hypothesis that the experience of high levels of acculturative stress would be associated with higher scores on the depressive symptoms measure, even when controlling for other demographic factors. This is consistent with past literature that links acculturative stress and depression in groups of international students (Constantine et al., 2004; Fritz, Chin, \& DeMarinis, 2008; Huang \& Mussap, 2018). This finding gives support to the idea that international students who experience higher levels of culture-related stress may also experience more internalizing symptoms, which has important implications for the treatment of these concerns. It is possible that the treatment of internalizing symptoms among international students would also necessitate a focus on the stress of acculturating to a new environment and host society. We also observed that higher levels of perceived discrimination were associated with greater depressive symptoms, in line with our hypothesis. This finding converges with literature suggesting that perceived discrimination negatively impacts psychological well-being and adjustment problems among immigrant populations in Europe (Jasinskaha-Lahti et al., 2006) and among various groups of international students (Duru \& Poyrazli, 2011; Poyrazli \& Lopez, 2007).

As this study examines acculturative stress and perceived discrimination simultaneously in relation to depressive symptoms, it is interesting that both were significantly associated with increased symptomatology. Discrimination stress related to culture or ethnic background has generally been thought of as a dimension of acculturative stress (Sandhu \& Asrabadi, 1994). The finding that perceived discrimination uniquely contributed to the increase in depressive symptoms above and beyond the effects of acculturative stress suggests that perceived discrimination may be especially salient for the international student population, regardless of its impact on their acculturation process.

Study results also supported our hypothesis that higher levels of social support would be associated with lower levels of depressive symptoms. This finding is in line with the previous findings of Sumer et al.'s (2008) study of international students and is consistent with the broader literature on stress and coping, which suggests that social support can contribute to the enhancement of well-being and positive mental health outcomes and is linked to an increased ability to handle stressful events (Andre de Araujo, 2011). Students with more social support are likely better able to navigate the stressful transition to life as a student in the US and suffer fewer depressive symptoms as a result. 
Taken together, results from this study provide strong evidence for the importance of social support networks for international students transitioning to life on a U.S. college campus. The study also suggests the important roles that acculturative stress and perceived discrimination may play with regard to negative mental health outcomes. These findings additionally have implications for university services, which are discussed further below.

\section{Study Limitations}

These findings must be interpreted in light of study limitations. This study is correlational in nature and therefore does not allow us to draw inferences about causal relationships between any of the variables. It is conceivable that high levels of anxiety or depressive symptoms could lead to acculturative stress, the perception of discrimination, or a lack of adequate social support networks.

Additionally, the measures were all gathered through self-report methods, and it is possible that social desirability effects or a belief that results could be traced back to respondents affected participant reporting. These types of measures can also suffer from auto-correlation effects. Some students reported low levels of English proficiency and yet completed the survey in English, which may have impacted their reporting on study variables.

Although we employed measures that have been successfully used with international students in the past, it is possible that the use of certain measures outside of their cultural context had limited relevance for the students from different regions. Depressive or anxiety symptoms may manifest differently across various cultures, or measures could have been interpreted within a participant's own cultural viewpoint, leading to culturally biased results. Despite the fact that we obtained a large sample, the regional sub-sample groupings were extremely uneven, and for this reason we did not compare students from the various regions on study variables, as in some cases we would be comparing only a handful of students from one country to several hundred from another. Although we split the sample into Asian and non-Asian groupings on several study variables, these regions are very heterogeneous, and culture can vary widely from country to country, even within the Asian region.

In the future, researchers could employ stratified random sampling in order to obtain equal representation from all regions and to have a random sample. This would allow for sub-analyses of group differences between various regions or even countries. Future research could include a longitudinal study that surveys international students in their home countries and then again at various time points during their time at the host university. This type of study could provide rich data for an in-depth understanding of the process of acculturation and its impact on psychosocial adjustment; this method could additionally allow for an examination of causal mechanisms. Additionally, a global comparative perspective of depressive symptoms among international students studying in other leading host nations, such as Australia and the UK, could serve as an interesting springboard for future research. 


\section{Implications and Conclusions}

The growing number of international students enrolled on U.S. campuses presents many challenges to university administrators and mental health services providers. Understanding the experiences and needs of international students has important consequences for decision-making around the structure and provision of on-campus services. Despite this study's limitations, there are several important implications for international student services on campuses in the US. Previous research suggests that international students drastically underuse available mental health services on campus (Andrade, 2006; Liu, 2009; Mori, 2000; Pedersen, 1991). A study in one university counseling center (Nilson, Berkel, Flores, \& Lucas, 2004) found that international students made up $8 \%$ of the student body but represented only $2.6 \%$ of clients seen at the counseling center that year, whereas minority students with comparable demographics were seen at the counseling center at much higher rates.

Potential reasons for the underuse of mental health services by international students include cultural beliefs about mental health, the perception that counselors will not understand students' culture or problems, and the perception that services are not accessible (Mori, 2000; Yi et al., 2003). Results of the current study demonstrate that international students indicate that they are suffering from high rates of depressive and anxiety symptoms and could potentially benefit from the help of counseling centers. Universities could increase outreach on campus to target international students and make them aware of the available services. Culturally appropriate services, including service provision in a student's own native language when possible, might put international students more at ease in a counseling situation (Constantine, Kindaichi, Okazaki, Gainor, \& Baden, 2005; Pedersen, 1991; Yi et al., 2003). Counseling services could be provided through informal networks, keeping in mind that research has found that the cultural norms of some societies cause international students to be wary of seeking out counseling services (Liu, 2009).

The results of this study demonstrate that perceived discrimination is prevalent and important even above and beyond general acculturative stress. This provides several implications for college student intervention services. To lessen the discrimination on campus, universities could actively engage both their American students and international students around ideas of tolerance, appreciation of diversity, and intercultural learning (Mori, 2001). Another way to potentially lessen perceived discrimination on campus and to provide students with increased social support would be to initiate peer-to-peer programs or partnerships, in which international students are paired with a motivated U.S. student to have informal discussions, coffee breaks, or perform service activities together. These types of outreach activities could promote cultural understanding and could also be a good way for international students to feel more welcomed by the host students on campus and to ultimately decrease the amount of isolation and discrimination against international students on campus (Abe, Talbot, \& Geelhoed, 1998; Pedersen, 1991).

Findings from this study suggest that high levels of social support may help international students avoid depressive symptoms. Counseling services for international students could include social support groups for students to help them find social support networks in the area and to connect with other students (Dipelou, Kang, \& Cooper, 2007). 
Universities could encourage international students to join extracurricular activities or clubs as a way for them to form social bonds on campus and interact with the campus community. International student services could also link their international students with more formal support networks on campus such as placement in host families throughout the duration of their stay (Liu, 2009). University administrators, student support units, and counseling centers should be aware that social support plays an important role for international students in relation to depressive symptoms and take steps appropriate to their unique university situation to ensure that international students have an opportunity to form social bonds during their time on campus. Future research is needed to better understand the moderating influence of social support on depressive symptoms in international students, and the factors that influence the prevalence of depressive symptoms within different national and regional international student groups.

\section{References}

Abe, J., Talbot, D. M., \& Geelhoed, R. J. (1998). Effects of a peer program on international student adjustment. Journal of College Student Adjustment, 39(6), 539-547.

Andrade, M. S. (2006). International students in English speaking universities: Adjustment factors. Journal of Research in Higher Education, 5, 131-154.

Araujo, A. (2011). Adjustment issues of international students enrolled in American colleges and universities: A review of the literature. Higher Education Studies, 1, 2-8.

Atri, A., Sharma, M., \& Cottrell, R. (2007). Role of social support, hardiness, and acculturation as predictors of mental health among. volume 27.

Beck, A. T., Epstein, N., Brown, G., \& Steer, R. A. (1988). An inventory for measuring clinical anxiety: Psychometric properties. Journal of Consulting and Clinical Psychology, 56(6), 893-897.

Bhochhibhoya, A., Dong, Y., \& Brancscum, P. (2017). Sources of social support Among international college students in the United States. Journal of International Students, 7(3), 671-686.

Botha, F. B., Shamblaw, A. L., \& Dozois, D. J. (2017). Reducing the stigma of depression among Asian students: A social norm approach. Journal of Cross-Cultural Psychology, 48(1), 113-131.

Briggs, P. \& Ammigan, R. (2017). A collaborative programming and outreach model for international student support offices. Journal of International Students, 7(4), 1080-1095.

Chang, M. X. L., Jetten, J., Cruwys, T., \& Haslam, C. (2017). Cultural identity and the expression of depression: A social identity perspective. Journal of Community \& Applied Social Psychology, 27(1), 16-34.

Chuah, J. S. \& Singh, M. K. M. (2016). International students' perspectives on the importance of obtaining social support from host national students. International Education Studies, 9(4), 132-140.

Cohen, S. \& Wills, T. A. (1985). Stress, social support, and the buffering hypothesis. Psychological Bulletin, 98(2), 310-357.

Constantine, M. G., Kindaichi, M., Okzakai, S., Gainor, K. A., \& Baden, A. L. (2005). A qualitative investigation of the cultural adjustment. volume 11. 
Constantine, M. G., Okazaki, S., \& Utsey, S. O. (2004). Self-concealment, social selfefficacy, acculturative stress, and depression in African, Asian, and Latin American college students. American Journal of Orthopsychiatry, 74(3), 230-241.

Crano, S. L. \& Crano, W. D. (1993). A measure of adjustment strain in international students. Journal of Cross-Cultural Psychology, 24(3), 267-283.

Creamer, M., Foran, J., \& Bell, R. (1995). The Beck Anxiety Inventory in a non-clinical sample. Behavior Research and Therapy, 33(4), 477-485.

Cross, S. E. (1995). Self-construals, coping, and stress in cross-cultural adaptation. Journal of Cross-Cultural Psychology, 26(6), 673-698.

Cujipers, P., Cristea, I. A., Ebert, D. D., Koot, H. M., Auerbach, R. P., Bruffaerts, R., \& Kessler, R. C. (2015). Psychological treatment of depression in college students: A meta-analysis. Depression and Anxiety, 33, 400-414.

Dipelou, A., Kang, J., \& Cooper, C. (2007). Support group for international students. Journal of College Student Psychotherapy, 22(1), 63-74.

Duru, E. \& Poyrazli, S. (2011). Perceived discrimination, social connectedness, and other predictors of adjustment difficulties among Turkish international students. International Journal of Psychology, 46(6), 446-454.

Eisenberg, D., Golberstein, E., \& Hunt, J. (2009). Mental health and academic success in college. The B E Journal of Economic Analysis \& Policy, 9, 40-41.

Eisenberg, D., Gollust, S. E., Golberstein, E., \& Hefner, J. L. (2007). Prevalence and correlates of depression, anxiety, and suicidality among college students. American Journal of Orthopsychiatry, 77, 534-542.

Eisenberg, D., Hunt, J., \& Speer, N. (2013). Mental health in American colleges and universities: Variation across student subgroups and across campuses. Journal of Nervous and Mental Disease, pages 60-67.

Feagin, J. R. \& Eckberg, D. L. (1980). Discrimination: Motivation, action, effects, and context. Annual Review of Sociology, 6, 1-20.

Forbes-Mewett, H. (2016). Exploring the social and academic experiences of international students in higher education institutions. IGI Global, Hershey, PA.

Fritz, M. V., Chin, D., \& DeMarinis, V. (2008). Stressors, anxiety, acculturation, and adjustment among international and North American students. International Journal of Intercultural Relations, 32, 244-259.

Hanassab, S. (2006). Diversity, international students, and perceived discrimination: Implications for educators and counselors. Journal of Studies in International Education, 10(2), 157-172.

Hill, R. M., Yaroslavsky, I., \& Pettit, J. W. (2015). Enhancing depression screening to identify college students at risk for persistent depressive symptoms. Journal of Affective Disorders, 174, 1-6.

Hsieh, M. (2006). Identity negotiation among female Chinese international students in second-language higher education. College Student Journal, 40, 870-884.

Huang, S. \& Mussap, A. (2018). Maladaptive Perfectionism, Acculturative Stress and Depression in Asian International University Students. Journal of Psychologists and Counsellors in Schools, 28(2), 185-196. 
Jansson-Frojmark, M. \& Lindblom, K. (2008). A bidirectional relationship between anxiety and depression, and insomnia? A prospective study in the general population. Journal of Psychosomatic Research, 64(4), 443-449.

Jasinskaha-Lahti, I., Liebkind, K., Jaakkola, M., \& Reuter, A. (2006). Perceived discrimination, social support networks, and psychological well-being among three immigrant groups. Journal of Cross-Cultural Psychology, 37(3), 293-311.

Karuppan, C. M. \& Barari, M. (2011). Perceived discrimination and international students' learning: an empirical investigation. Journal of Higher Education Policy and Management, 33, 67-83.

Kawamoto, A., Youn, S. J., Bartholomew, T. T., Castonguay, L. G., \& Locke, B. D. (2018). Interand intra-group differences in psychological concerns among international students. Counselling Psychology Quarterly, 31(2), 186-204.

Kelo, M., Rogers, T., \& Rumbley, L. (2010). International student support in European higher education needs, solutions and challenges.

Lee, J. J. \& Rice, C. (2007). Welcome to America? International student perceptions of discrimination. Higher Education, 53(3), 381-409.

Lipson, S. K., Gaddis, S. M., Heinze, J., Beck, K., \& Eisenberg, D. (2015). Variations in student mental health and treatment utilization across US colleges and universities. Journal of American College Health, 63(6), 388-396.

Liu, M. (2009). Addressing the mental health problems of Chinese international college students in the United States. Advances in Social Work, 10(1), 69-86.

Luo, J. \& Jamieson-Drake, D. (2013). Examining the educational benefits of interacting with international students. Journal of International Students, 3(2), 85-101.

Mackenzie, S., Wiegel, J. R., Mundt, M., Brown, D., Saewyc, E., \& Heiligenstein, E. (2011). Depression and suicide ideation among students accessing campus healthcare. American Journal of Orthopsychiatry, 81, 101-107.

Mackinnon, A., McCallum, J., Andrews, G., \& Anderson, I. (1998). The Center for Epidemioloigcal Studies Depression Scale in older community samples in. The Journals of Gerontology, Series B: Psychological Sciences and Social Sciences, 53(6), 343-352.

Martens, M. P., Martin, J., Hatchett, S., Fowler, R. F., Fleming, K., Karakashian, M., \& Cimini, M. D. (2008). Protective behavioral strategies and the relationship between depressive symptoms and alcohol-related negative consequences among college students. Journal of Counseling Psychology, 55, 535-541.

Mori, S. C. (2000). Addressing the mental health concerns of international students. Journal of Counseling \& Development, 78, 137-144.

Msengi, I. G. (2004). Sources of Stress and its impact on health behaviors and academic performance of international students at a comprehensive midwestern university. International Journal of Global Health and Health Disparities, 5, 55-69.

Nilson, J. E., Berkel, L. A., Flores, L. Y., \& Lucas, M. S. (2004). Utilization rate and presenting concerns of international students at a university counseling center. Journal of College Psychotherapy, 19(2), 49-59.

Pedersen, P. B. (1991). Counseling international students. The Counseling Psychologist, 19(1), 10-58. 
Perrucci, R. \& Hu, H. (1995). Satisfaction with social and educational experiences among international graduate students. Research in Higher Education, 36(4), 491-508.

Poyrazli, S. \& Kavanaugh, P. R. (2006). Marital status, ethnicity, academic achievement, and adjustment strains: The case of graduate international students. College Student Journal, 40(4), 767-780.

Poyrazli, S. \& Lopez, M. D. (2007). An exploratory study of perceived discrimination and homesickness: A comparison of international students and American students. Journal of Psychology, 141(3), 263-280.

Poyrazli, S., Thukral, R. K., \& Duru, E. (2010). International students' race-ethnicity, personality, and acculturative stress. Journal of Psychology and Counseling, 2(8), 25-32.

Radloff, L. (1977). The CES-D scale: A self-report depression scale for research in the general population. Applied Psychological, 1(3), 385-401.

Rice, G., Choi, C. C., Zhang, Y., Morero, Y. I., \& Anderson, D. (2012). Self-critical perfectionism, acculturative stress, and depression among international students. The Counseling Psychologist, 40(4), 575-600.

Sam, D. L. (2001). Satisfaction with life among international students: an exploratory study. Social Indicators Research, 53(3), 315-337.

Sandhu, D. S. \& Asrabadi, B. R. (1994). Development of an acculturative stress scale for international students: Preliminary findings. Psychological Reports, 75(2), 435-448.

Steptoe, A., Tsuda, A., Tanaka, Y., \& Wardle, J. (2007). Depressive symptoms, socioeconomic background, sense of control, and cultural factors in university students from 23 countries. International Journal of Behavioral Medicine, 14(2), 97-107.

Sumer, S., Poyrazli, S., \& Grahame, K. (2008). Predictors of depression and anxiety among international students. Journal of Counseling \& Development, 86, 429-437.

Torres, L. (2010). Predicting levels of Latino depression: Acculturation, acculturative stress, and coping. Cultural Diversity and Ethnic Minority Psychology, 16, 256-263.

Wadsworth, B. C., Hecht, M. L., \& Jung, E. (2008). The role of identity gaps, discrimination. Communication Education, 57, 64-87.

Wei, M., Heppner, P. P., Ku, T. Y., \& Liao, K. Y. H. (2010). Racial discrimination stress, coping, and depressive symptoms among Asian Americans: A moderation analysis. Asian American Journal of Psychology, 1, 136-150.

Wei, M., Ku, T., Russell, D. W., Mallinckrodt, B., \& Liao, K. Y. (2008). Moderating effects of three coping strategies and self-esteem on perceived discrimination and depressive symptoms: A minority stress model for international students. Journal of Counseling Psychology, 55, 451-462.

Williams, D. R., Yu, Y., \& Jackson, J. S. (1997). Racial differences in physical and mental health: Socio-economic status, stress, and discrimination. Journal of Health Psychology, 2(3), 335-351.

Wood, M. \& Kia, P. (2000). International student affairs. New Directions for Higher Education, 2000(111), 55-64.

Yeh, C. J. \& Inose, M. (2003). International students' reported English fluency, social support satisfaction, and social connectedness as predictors of acculturative stress. Counseling Psychology Quarterly, 16, 15-28. 
Yi, J. K., Lin, J. G., \& Kishomoto, Y. (2003). Utilization of counseling services by international students. Journal of Instructional Psychology, 30(4), 333-342.

Ying, Y. \& Liese, L. H. (1994). Initial adjustment of Taiwanese students to the United States: The impact of postarrival variables. Journal of Cross-Cultural Psychology, 25(4), 466-477.

\section{Author biography}

Noel L. Shadowen is a post-doctoral researcher at the Center for Training, Evaluation, \& Community Collaboration at the University of Delaware, USA.

Ariel A. Williamson is a psychologist at the Children's Hospital of Philadelphia, USA.

Nancy G. Guerra is Dean, School of Social Ecology and Professor, Department of Psychology and Social Behavior at the University of California, Irvine, USA.

Ravichandran Ammigan is Executive Director of the Office for International Students and Scholars at the University of Delaware, USA.

Matthew L Drexler is Assistant Director for Student Engagement at the Office for International Students and Scholars, University of Delaware, USA. 